\title{
Repetitive transcranial magnetic stimulation for the treatment of anxiety disorders: A systematic review of the state-of-the-art
}

\author{
Luis F. Burguete-Castillejos, Flavio A. Domínguez-Pacheco, and Claudia L. Martínez-González* \\ SEPI ESIME Zacatenco, Instituto Politécnico Nacional, Mexico City, Mexico
}

\begin{abstract}
Psychiatric disorders, particularly related to depression and anxiety, are emerging as the most disabling diseases of the new era. Finding different intervention methods to treat these conditions is a public health challenge. Thus, exploring the results obtained by transcranial magnetic stimulation (TMS) is critical since this neurostimulation technique could position itself as a blunt alternative to manage anxiety pathologies. In this review, a systematic search for TMS use in anxiety disorders was carried out based on the PRISMA criteria. It was found that the most effective protocol for TMS treatment for anxiety disorders is performed with low-frequency stimulation $(1 \mathrm{~Hz})$, with $110 \%$ of the motor threshold. Furthermore, repeated TMS has proven its effectiveness in different psychiatric disorders - not only as a therapeutic alternative but also in the search for neurological biomarkers-. TMS favors neuromodulation through the generation of action potentials, which facilitates the treatment of pathologies related to emotional components, such as anxiety. However, further research is needed to specify the neurobiological mechanisms present in the improvement of symptoms.
\end{abstract}

Keywords: Anxiety disorders. Neurostimulation. Repeated transcranial magnetic stimulation.

\section{Estimulación magnética transcraneal repetitiva (EMTr) para el tratamiento de trastornos de ansiedad: una revisión sistemática del estado del arte}

\section{Resumen}

Los trastornos psiquiátricos, particularmente los relacionados con depresión y ansiedad, se perfilan paulatinamente como las enfermedades más discapacitantes de la nueva era. Hallar diferentes métodos de intervención para tratar estas condiciones es un reto de salud pública. Por consecuencia, explorar los resultados obtenidos por la estimulación magnética transcraneal (EMTr) es crítico, ya que esta técnica de neuroestimulación puede posicionarse como una alternativa contundente para manejar las patologías de la ansiedad. En esta revisión se llevó a cabo una búsqueda sistemática del uso de la EMTr en trastornos de ansiedad con base en los criterios de PRISMA. Se encontró que el protocolo más efectivo de EMTr para trastornos de ansiedad se realiza a frecuencias bajas $(1 \mathrm{~Hz})$ y el área cortical estimulada es la prefrontal dorsolateral derecha. Además, la EMTr repetida ha probado su efectividad en diferentes trastornos psiquiátricos, no sólo como alternativa terapéutica, sino en la búsqueda de biomarcadores neurológicos. La EMTr favorece la neuromodulación a través de la generación de potenciales de acción, lo cual facilita el tratamiento de patologías relacionadas con componentes emocionales como la ansiedad. Sin embargo, aún se requiere mayor investigación para especificar los mecanismos neurobiológicos presentes en el mejoramiento de los síntomas.

Palabras clave: Trastornos de ansiedad. Neuroestimulación. EMTr.

\section{Correspondence:}

*Claudia L. Martínez-González

E-mail: clmartinezg@ipn.mx
Date of reception: $12-12-2020$

Date of acceptance: 19-05-2021

DOI: $10.24875 /$ RMN.20000130
Available online: 03-01-2022

Rev Mex Neuroci. 2022;23(1):22-28 www.revmexneurociencia.com 2604-6180 / @ 2021 Academia Mexicana de Neurología A.C. Published by Permanyer. This is an open access article under the CC BY-NC-ND license (http://creativecommons.org/licenses/by-nc-nd/4.0/). 


\section{Introduction}

Anxiety and depression are the most widespread mental disorders, most prevalent in low- and middle-income countries - whose rate remains increasing in the world population due to social, economic, physical, and patient context factors ${ }^{1}$. This situation will generate more significant chain conflicts, and if the global burden of mental illness is considered, it will imply that contemporary society will eventually begin to need not only a higher amount of clinical alternatives to address these pathologies but more effective methods and techniques to treat them.

Then, clinical models for treating anxiety problems should consider this phenomenon from a transdisciplinary point of view, not to replace traditional intervention models, but to add the participation of neurosciences together with the use of technological tools ${ }^{2}$.

Transcranial magnetic stimulation (TMS) is an unorthodox and avant-garde treatment for clinical intervention ${ }^{3}$. Compared with traditional psychopharmacology, which aims to treat neurobiological mechanisms, TMS generates a stimulation directly in the functioning of any region of the cerebral cortex, both in inhibitory and excitatory neuronal circuits ${ }^{3}$. On the other hand, TMS affects neurophysiological processes and neurobiochemicals, without being invasive like some other procedures ${ }^{4}$, since it favors the depolarization of the membrane of neurons (Fig. 1) by generating a sufficient electromagnetic field to trigger action potentials ${ }^{5}$.

Compared to direct electrical stimulation, TMS allows stimulation to act more focally 4 . It has been considered that simple magnetic pulses or "trains" (pulse bursts) are capable of depolarizing the membrane of a group of neurons, either from some axon or some dendritic feet, initiating an exciting, or inhibiting chain reaction ${ }^{3}$.

The theoretical principles of magnetic induction proposed by Michael Faraday toward 1831 are the basis of the TMS. However, until 1984, Anthony Barker et al. managed, through extensive research, to develop a neurostimulator that could generate depolarization of cortical neurons, causing movements ${ }^{3}$. Eventually, the development of the stimulation technique gained its characteristics and stimulation parameters to turn it into what is currently known as the TMS.

TMS is a technique with a mechanism of action that consists in the application of a magnetic field (magnetic pulses) of defined intensity which is produced by a coil going through not only the skull but also the scalp of a person to reach the cerebral cortex, where it will affect, inhibiting or exciting, and neuronal function (Fig. 2) ${ }^{6}$.

Practically, for a magnetic neurostimulator to produce a magnetic field that is capable of stimulating cortical neurons, it must use an electric current intensity of 7-10 $\mathrm{kA}$, which is produced by an energy capacitor, a charging circuit, and one of discharge, as well as with an electronic switch that flows through a coil up to $500 \mathrm{~J}$ in the form of a pulse of approximately 1-ms duration?

This treatment has been well received by multiple international clinical institutions as a "non-experimental" medical treatment for psychiatric conditions, especially for the effective treatment for major depression and promising usefulness for social anxiety treatment ${ }^{8}$. Related to panic disorder, a study conducted by Dresler in 2009 reported a case in which TMS was able to modulate cortical functions during an emotional crisis, that is, a panic attack ${ }^{9}$.

The objectives of this review were to analyze how effective the TMS intervention has been found in anxiety disorders - according to the characteristics of the samples and the experimental designs - and to determine the implications for future interventions based on the PRISMA criteria ${ }^{10}$.

\section{Anxiety disorders}

Anxiety is an emotional state in which humans naturally express to certain environmental stimuli. Thus, anxiety, understood as a physiological chain reaction activated by the autonomic nervous system, alerts individuals to dangerous situations that arise in the surroundings manifesting itself as adaptive defensive behavior that allows human survival.

\section{Methodology}

A specific search was conducted in the scientific research repositories such as PUBMED, Neurology, Medline, Elsevier, and others that meet international criteria until 2020. The first search was performed using the following keywords:

Panic disorder AND Magnetic transcranial stimulation OR Repetitive magnetic transcranial stimulation OR TMS, Generalized Anxiety Disorder AND symptoms OR state, Social Anxiety Disorder OR specific phobia OR depression AND anxiety, depersonalization disorder OR Parkinson AND depression AND anxiety. These results were included by virtue that it could be analyzed how efficient repeated TMS (rTMS) was for anxiety symptoms. 


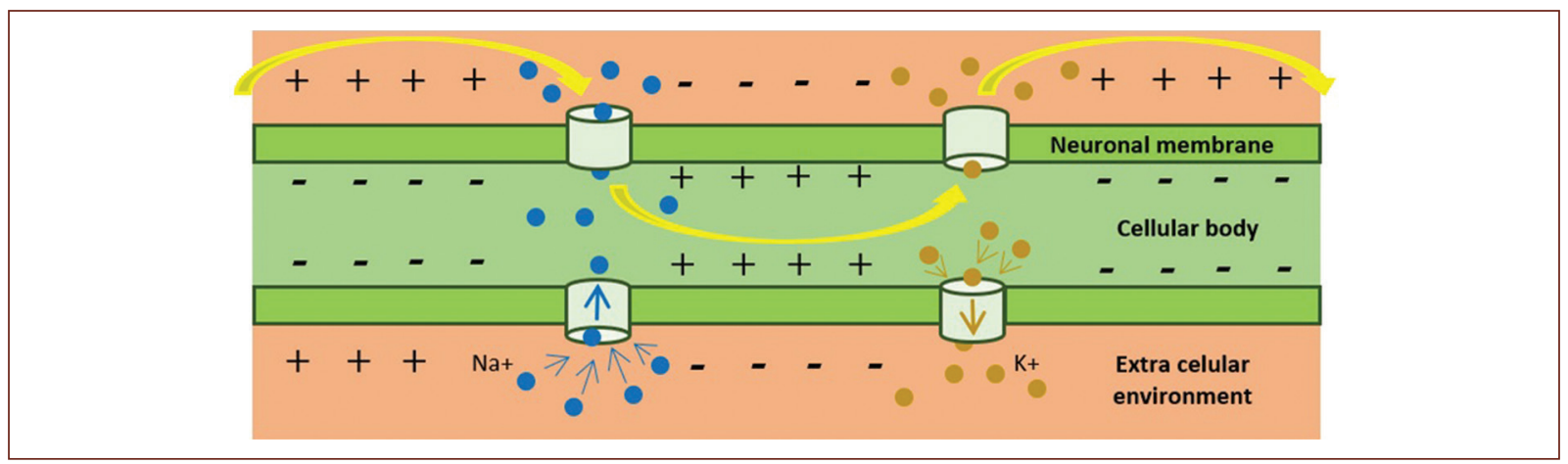

Figure 1. Depolarization is the process that allows the transmission of the nerve impulse when there is a change of charge between the outside of the membrane, from positive to negative, and the inside, from negative to positive. This process enables the transmission of the nerve impulse and, therefore, of the neuronal intercommunication.

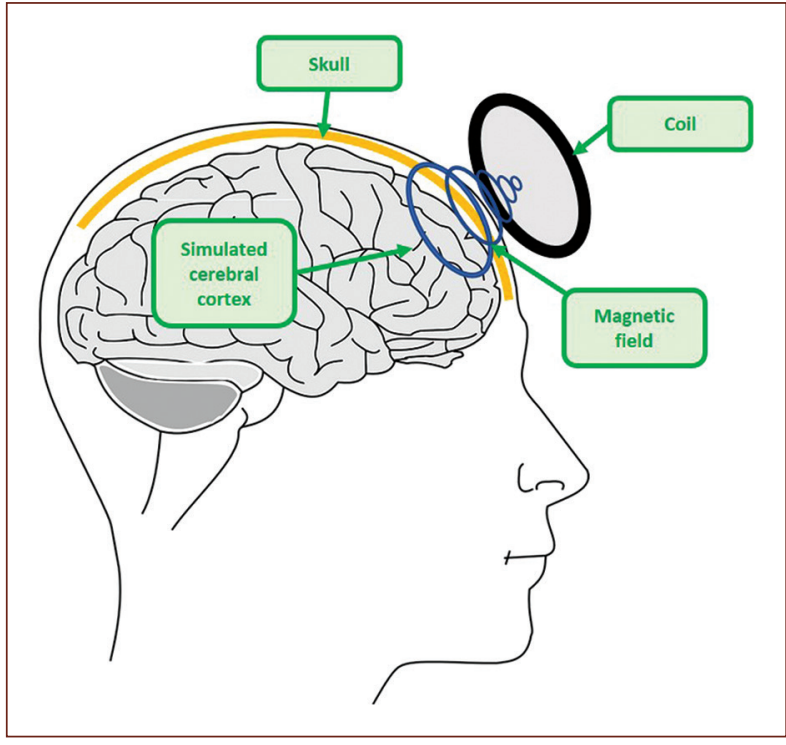

Figure 2. Principles of transcranial magnetic stimulation. Sagittal brain section.

Various studies were selected according to the following inclusion criteria presented in Table 1.

During the systematic review, research was found, beyond anxiety itself, highlighting emotional processing and, in some cases, using a technique with the same physical principle as TMS, called Intermittent Tetha Burst Stimulation (iTBS) or Intermittent Stimulation of Theta bursts. Unlike rTMS, which application varies from values below $1 \mathrm{~Hz}$ to $50 \mathrm{~Hz}$, iTBS provides 10 bursts of three biphasic pulses of $100 \mu \mathrm{s}$ at $50 \mathrm{~Hz}$ repeated at $200 \mathrm{~ms}$ intervals, that is, $5 \mathrm{~Hz}$ at theta frequency ${ }^{11}$.
Table 1. Inclusion and exclusion criteria for literature search

\begin{tabular}{|l|l|}
\hline Inclusion criteria & Exclusion criteria \\
\hline Date of recent publication & $\begin{array}{l}\text { Date of non-recent } \\
\text { publication }\end{array}$ \\
\hline $\begin{array}{l}\text { Date of publication not recent that } \\
\text { provide information to } \\
\text { contextualize the subject or lay } \\
\text { historical foundations of the topics }\end{array}$ & $\begin{array}{l}\text { Date of non-recent } \\
\text { publication and obsolete } \\
\text { information }\end{array}$ \\
\hline $\begin{array}{l}\text { TMS is applied to some anxiety } \\
\text { disorder }\end{array}$ & $\begin{array}{l}\text { TMS was not applied to } \\
\text { any psychiatric disorder }\end{array}$ \\
\hline $\begin{array}{l}\text { Explains the TMS application } \\
\text { protocol }\end{array}$ & \\
\hline $\begin{array}{l}\text { Explains the consequences of the } \\
\text { application of TMS }\end{array}$ & \\
\hline
\end{tabular}

Selected documents were classified according to the information and type of research. Thus, the literature search was performed as presented in Fig. 3. The information extracted from the articles was organized to recognize the characteristics of the sample, experimental design, inclusion and exclusion criteria, the method and instrument of intervention, adverse symptoms, and results. The articles were rated according to the guidelines of the PEDro Scale ${ }^{12}$.

\section{Results}

The papers selected for the critical analysis of this systematic review are presented in Table 1. It is worth 


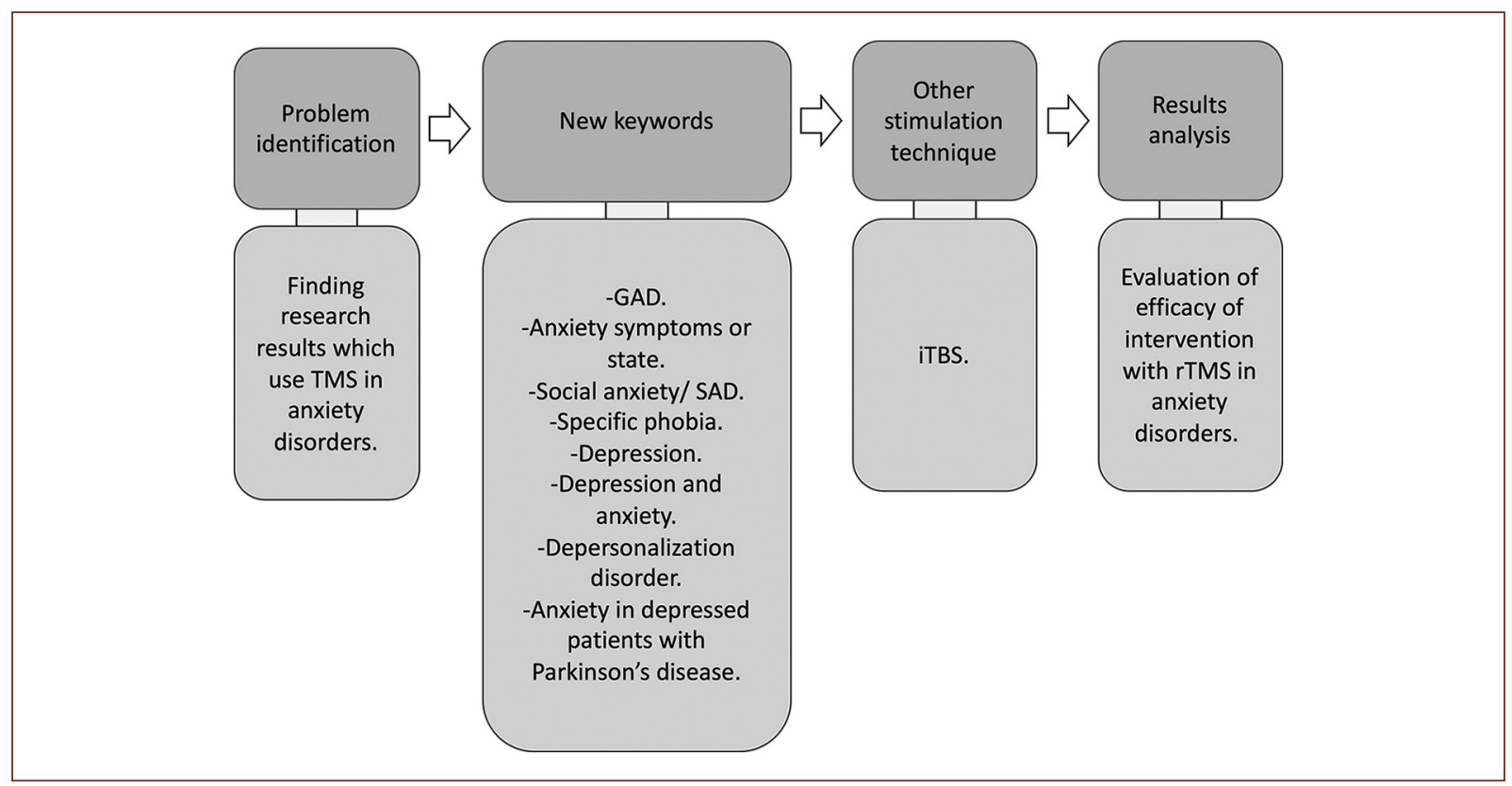

Figure 3. Literature search process.

noting that the intervention method and the results were highlighted since this allows determining whether rTMS is emerging as a useful technique for anxiety disorder treatment and other disorders that also present anxiety symptoms.

\section{Discussion}

It was found that TMS, applied as a non-invasive intervention technique, is effective for different psychiatric disorders. Although the results of rTMS have been mostly studied in depression, it has been found that enough research has also been done in other pathologies such as those of anxiety.

The results have been organized and classified according to the effectiveness of treatment through rTMS, according to data within table 2 .

\section{Studied disorders}

According to the 34 studies collected $(33=100 \%$, considering the references Machado et $a .^{15}$ and Paes et al. ${ }^{17}$ report two investigations), $66.66 \%$ were carried out with some specific disorder or symptoms of anxiety $(23=100 \%)$. Therefore, $35.29 \%$ were performed with panic disorder, $17.64 \%$ were performed with phobic disorders, and $47.05 \%$ were performed with anxiety symptoms or some unspecified disorder of anxiety.

\section{Sample description}

Regarding the sample size, $36.36 \%$ of the studies were conducted with 30 or more participants. Samples of 67 and 40 patients were used for the disorder of panic, other samples of 25 and 30 patients were used for anxiety symptoms or some disorder of anxiety not specified and, in the case of phobias, all the samples were between 41 and 30 patients.

In general, these studies were carried out in hospitals. On the other hand, $64.70 \%$ were performed with very variable samples from $<30$ patients. For example, in generalized anxiety, it was found that an investigation used a sample of 25 patients and other 10 . There was more variability for the panic disorder since small samples were found between three and 15 volunteers; the same happened for symptoms or some unspecified disorder of anxiety, where samples were presented in the range of 10 to 28 participants.

Table 3 describes some other attributes of samples specified in the papers found during the systematic search.

\section{Criteria for inclusion and exclusion of studies}

Due to the inclusion and exclusion criteria, roughly, subjects had to be diagnosed according to specific scales with the study pathology, and in counterpart, not 
Table 2. Organization of investigations according to effectiveness results

\begin{tabular}{|c|c|c|}
\hline $\begin{array}{l}\text { Disorder/mental } \\
\text { process }\end{array}$ & Effective treatment & $\begin{array}{l}\text { Non-effective } \\
\text { treatment }\end{array}$ \\
\hline $\begin{array}{l}\text { Disorder of panic/ } \\
\text { anguish }\end{array}$ & $\begin{array}{l}\text { García-Toro et al. }{ }^{14} \\
\text { Machado et al. } \\
\text { Mantovani et al. }\end{array}$ & $\begin{array}{l}\text { Deppermann } \\
\text { et al. }{ }^{43} \text {; } \\
\text { Zwanzger } \\
\text { et al. }{ }^{41}\end{array}$ \\
\hline $\begin{array}{l}\text { Disorder of general } \\
\text { anxiety }\end{array}$ & Diefenbach et al. ${ }^{13}$ & \\
\hline $\begin{array}{l}\text { Anxiety/symptoms/ } \\
\text { state of anxiety/fear } \\
\text { and anxiety }\end{array}$ & $\begin{array}{l}\text { Balconi and } \\
\text { Ferrari }^{19,20,26 ;} \\
\text { Machado et al. }{ }^{15} ; \\
\text { Vanderhasselt et al al. }{ }^{23} \text {; } \\
\text { Zwanzger et al. } .^{28}\end{array}$ & $\begin{array}{l}\text { Baeken } \\
\text { et al. }{ }^{24} \text {; } \\
\text { Vanderhasselt } \\
\text { et al. }{ }^{25}\end{array}$ \\
\hline $\begin{array}{l}\text { Anxiety/social } \\
\text { phobia }\end{array}$ & $\begin{array}{l}\text { Pallanti et al }{ }^{36} ; \\
\text { Balderson et al. }{ }^{45}\end{array}$ & \\
\hline Specific phobia & $\begin{array}{l}\text { Deppermann et al. }{ }^{29} \text {; } \\
\text { Herrmann }^{30}\end{array}$ & $\begin{array}{l}\text { Deppermann } \\
\text { et al. }{ }^{33} ; \\
\text { Notzon et al. }{ }^{34}\end{array}$ \\
\hline $\begin{array}{l}\text { Anxious depression/ } \\
\text { depression and } \\
\text { anxiety }\end{array}$ & $\begin{array}{l}\text { Diefenbach et al. }{ }^{18} \\
\text { LaSalle-Ricci et al. }\end{array}$ & \\
\hline Depression & $\begin{array}{l}\text { Deppermann et al. }{ }^{29} \text {; } \\
\text { Fitzgerald et al. }{ }^{27}\end{array}$ & \\
\hline Depersonalization & Jay et al. ${ }^{16}$ & \\
\hline $\begin{array}{l}\text { Parkinson, anxiety } \\
\text { and depression }\end{array}$ & Kormos ${ }^{22}$ & \\
\hline $\begin{array}{l}\text { Automatic } \\
\text { emotional reactions/ } \\
\text { emotional } \\
\text { processing }\end{array}$ & $\begin{array}{l}\text { Berger et al. }{ }^{31} ; \\
\text { De Raedt et al. }\end{array}$ & $\begin{array}{l}\text { Vennewald } \\
\text { et al. }{ }^{32}\end{array}$ \\
\hline
\end{tabular}

Table 3. Other sample characteristics

\begin{tabular}{|l|c|}
\hline Sample characteristic & $\begin{array}{c}\text { Percentage of papers } \\
\text { indicating attributes }\end{array}$ \\
\hline Both genres & $14.70 \%$ \\
\hline Female gender & $14.70 \%$ \\
\hline Age range & $8.82 \%$ \\
\hline Over 18 years & $2.94 \%$ \\
\hline Over 40 years & $2.94 \%$ \\
\hline $\begin{array}{l}\text { Right-handed manual } \\
\text { preference }\end{array}$ & $20.58 \%$ \\
\hline Visual acuity & $5.88 \%$ \\
\hline
\end{tabular}

suffering any other disease of the central nervous system, psychiatric or neurological, or cardiovascular; only the concomitance of some other disease was allowed in Mantovani et al. ${ }^{39}$ and Mantovani et al. ${ }^{40}$ In none of the cases, the selection of volunteers was made according to gender.

\section{Intervention protocol and treatment efficiency}

Intervention protocol for anxiety disorders prevailing was $1 \mathrm{~Hz}$ with an intensity between 90 and $110 \%$ of the motor threshold, and it is essential to note that there is a correlation between stimulation characteristics and its results. Notably, in Zwanzger et al. ${ }^{41}$, treatment was carried out at a low frequency, but it was not performed repeatedly, and the results were not as expected. Regarding the results of Deppermann et al. ${ }^{43}$, no strong results were found since the registered psychophysiological arousal may be due to the tasks performed by those evaluated and not properly to the effects of stimulation; the results of Vanderhasselt et al. ${ }^{23}$ and Baeken et al. ${ }^{24}$ had no favorable effects because the stimulation was performed with high frequencies $(10 \mathrm{~Hz})$ as the frequency approved for depression.

Results presented in Deppermann et al. ${ }^{33}$ are inconclusive by virtue that it cannot be specified how stimulation modulates neuronal activation. On the other hand, Notzon ${ }^{34}$ stated that a single stimulation session is not enough to generate effects on phobic symptoms, and mainly the frequency of the protocol was not presented. The results presented in Balconi ${ }^{19,20}$ were favorable, although protocols with an intermediate intensity $(5 \mathrm{~Hz})$ were applied. In other words, $72.72 \%$ of the sources consulted showed favorable results after using the rTMS, while $27.27 \%$ indicated non-favorable or conclusive results, although it should be noted that the protocol is not the same in all cases. In this context, $68.18 \%$ stimulated the right dorsolateral prefrontal cortex, demonstrating that the efficacy of rTMS treatment for these types of disorders is achieved when this neuroanatomic region is stimulated, because it reduces hypermetabolism and neuronal hyperexcitability.

\section{Neurostimulation equipment used for rTMS}

The most used neurostimulator, as reported in the documents was Magstim ${ }^{18,19,22,23,25,42}$, followed by Dantec MagPRo ${ }^{14,28-30}$, and only one report ${ }^{13}$ used Neuronetics XPLOR, and other one MagVenture MagPro $100^{45}$. 


\section{Adverse reactions reported}

In the present review, Baeken et al. ${ }^{24}$ reported a secondary dermatological reaction; García-Toro et al. ${ }^{14}$, a patient who reported mild and transient headache, and Diefenbach et al. ${ }^{13}$ reported that one patient suffered pain at the stimulation site. Although the administration of this neurostimulation technique is endorsed by the Food and Drug Administration (FDA), results indicate that it is favorable, it has been indicated that research on the effects should continue. It is important to mention that research using functional neuronal evaluation tools in which clinical factors can be ruled out to demonstrate the effects of magnetic stimulation is needed.

In two studies, there was a control group analysis with a placebo effect ${ }^{13,43}$, and it was possible to show that magnetic stimulation was effective in Diefenbach et al. ${ }^{13}$, which is not in Deppermann's ${ }^{43}$.

\section{Limitations of this review}

Although conventional intervention methods, which include psychotherapy and pharmacology, have proven to be effective because both have been studied for a long time, protocols need to conclude whether magnetic stimulation effects are effective or not. About the above, it should be considered that subjective variables, that is, the references of the patients about their perception of improvement, do not allow a more objective analysis, and it is necessary to carry out the evaluation of the effect with functional and structural evaluation tools of the stimulated cortical areas.

On the other hand, it is worth noting that no studies were found in which rTMS has been used during a panic attack so that its effect on physiological or other variables could be understood in greater depth. In the same way, this systematic review of literature aimed to determine how effective rTMS is in anxiety disorders, highlighting the importance of continuing the research on the topic.

Regarding to the PEDro scale, one article fulfilled $100 \%$ of the criteria, six with $90.90 \%$, three with $27.27 \%$, one with $72.72 \%$, one with $63.63 \%$, and four with $54.54 \%$, while the rest of the works were found below this last percentage, so it could be said that half of the papers reported met at least more than half of the criteria established in the scale PEDro. In this regard, it is necessary for scientific research to demonstrate the usefulness of any clinical intervention, in this case the rTMS in anxiety disorders, and expose the risks of bias, either due to the characteristics of the samples or the non-contemplation of certain variables, as well as to break down their design, their procedures and results explicitly so that other researchers clearly know the benefits.

\section{Conclusions}

rTMS favors neuromodulation through the generation of action potentials ${ }^{6}$, which facilitates the treatment of pathologies related to emotional components, such as anxiety.

The most effective protocol to treat anxiety disorders with the reported rTMS uses low-frequency stimulation $(1 \mathrm{~Hz})$, with $110 \%$ of the motor threshold, applied on the right dorsolateral prefrontal cortex with a 30-min train 5 times a week, for a month.

Finally, the use of rTMS could favor efficacy of psychotherapeutic procedures since these are understood as methods favoring learning, and neurostimulation promotes neuroplasticity.

\section{Funding}

This paper was supported by the Instituto Politécnico Nacional (SIP 20200614) and the Consejo Nacional de Ciencia y Tecnología (CONACyT).

\section{Conflicts of interest}

We declare no conflicts of interest.

\section{Ethical disclosures}

Protection of human and animal subjects. The authors declare that no experiments were

performed on humans or animals for this study.

Confidentiality of data. The authors declare that no patient data appear in this article.

Right to privacy and informed consent. The authors declare that no patient data appear in this article.

\section{SUPPLEMENTARY DATA}

Supplementary data are available at DOI: 10.24875/ RMN.20000130. These data are provided by the corresponding author and published online for the benefit of the reader. The contents of supplementary data are the sole responsibility of the authors. 


\section{References}

1. Zorzela L, Loke YK, loannidis JP, Golder S, Santaguida P, Altman DG et al. PRISMA harms checklist: improving harms reporting in systematic reviews. BMJ. 2016;352:1157.

2. Koutsimani P, Montgomery A, Georganta K. The relationship between burnout, depression, and anxiety: a systematic review and meta-analysis. Front Psychol. 2019;10:284

3. Alonzo A, Aaronson S, Bikson M, Husain M, Lisanby S, Martin D, et al Study design and methodology for a multicentre, randomised controlled trial of transcranial direct current stimulation as a treatment for unipolar and bipolar depression. Contemp Clin Trials. 2016;51:65-71.

4. Pascual-Leone A, Tormos-Muñoz JM. Estimulación Magnética Transcraneal: fundamentos y Potencial de la Modulación de Redes Neurales Específicas; 2008. Available from: http://www.cecm.usp.br/ eris/pub/ artigos/cognicao/pascual-leone EMT.pdf. [Last accessed on 2018 Aug 28].

5. Jiménez-Genchi A, González-Olvera J, Guerrero AG. Las aplicaciones de la estimulación magnética transcraneal en psiquiatría. Salud Ment. 2002;25:033040.

6. Brunoni AR, Teng CT, Correa C, Imamura M, Brasil-Neto JP, Boechat R et al. Neuromodulation approaches for the treatment of major depression: challenges and recommendations from a working group meeting. Arq Neuropsiquiatr. 2010;68:433-51.

7. León M, Rodríguez ML, Sanjuán L, Benito-León J, García-Albea Ristol $E$, et al. Current evidence on transcranial magnetic stimulation and its potential usefulness in post-stroke neurorehabilitation: opening new doors to the treatment of cerebrovascular disease. Neurologia. 2018;33:459-72.

8. Pascual-Leone A. Handbook of transcranial magnetic stimulation. J Psychiatry Neurosci. 2003;28:373-5.

9. Pallanti S, Bernardi S. Neurobiology of repeated transcranial magnetic stimulation in the treatment of anxiety: a critical review. Int Clin Psychopharmacol. 2009;24:163-73.

10. Dresler T, Ehlis AC, Plichta MM, Richter MM, Jabs B, Lesch KP, et al. Panic disorder and a possible treatment approach by means of high-frequency rTMS: a case report. World J Biol Psychiatry. 2009;10:991-7.

11. Dieguez-Varela $C$, Lion-Vazquez S, Fraga-Bau A, Rodriguez-Acevedo B Rodriguez-Sanchez L, Collazo-Dieguez M, et al. Intermittent theta-burs transcranial magnetic stimulation for the treatment of spasticity in patients with recurring multiple sclerosis: the results of a double-blind randomised clinical trial. Rev Neurol. 2019;69:45-52.

12. Maher CG, Sherrington C, Herbert RD, Moseley AM, Elkins M. Reliability of the PEDro scale for rating quality of randomized controlled trials. Phys Ther. 2003;83:713-21.

13. Diefenbach GJ, Bragdon L, Zertuche L, Hyatt CJ, Hallion LS, Tolin DF et al. Repetitive transcranial magnetic stimulation for generalised anxiety disorder: a pilot randomised, double-blind, sham-controlled trial. $\mathrm{Br} J$ Psychiatry. 2016;209:222-8.

14. García-Toro M, Salva Coll J, Crespí Font M, Andrés Tauler J, Aguirre Orue I, Bosch Calero C. Trastorno de angustia y estimulación magnética transcraneal. Actas Esp Psiquiatr. 2002;30:221-4

15. Machado S, Paes F, Velasques B, Teixeira S, Piedade R, Ribeiro P, et al. Is rTMS an effective therapeutic strategy that can be used to treat anxiety disorders? Neuropharmacology. 2012;62:125-34.

16. Jay EL, Nestler S, Sierra M, McClelland J, Kekic M, David AS. Ventrolateral prefrontal cortex repetitive transcranial magnetic stimulation in the treatment of depersonalization disorder: a consecutive case series. Psychiatry Res. 2016;240:118-22.

17. Paes F, Baczynski T, Novaes F, Marinho T, Arias-Carrión O, Budde $H$ et al. Repetitive transcranial magnetic stimulation (rTMS) to treat social anxiety disorder: case reports and a review of the literature. Clin Pract Epidemiol Ment Health. 2013;9:180-8.

18. Diefenbach GJ, Bragdon L, Goethe JW. Treating anxious depression using repetitive transcranial magnetic stimulation. J Affect Disord. 2013;151:365-8

19. Balconi M, Ferrari C. Left DLPFC rTMS stimulation reduced the anxiety bias effect or how to restore the positive memory processing in high-anxiety subjects. Psychiatry Res. 2013;209:554-9.

20. Balconi M, Ferrari C. Repeated transcranial magnetic stimulation on dorsolateral prefrontal cortex improves performance in emotional memory retrieval as a function of level of anxiety and stimulus valence. Psychiatry Clin Neurosci. 2013;67:210-8.

21. LaSalle-Ricci VH, Sisko E, DeBlasio K, Tendler S, Allsup H, DeLuca L, et al. Early improvement of depression and anxiety symptoms with repetitive transcranial magnetic stimulation (rTMS) augmentation of medication: case series. Brain Stimul. 2014;7:e20-1.

22. Kormos TC. Efficacy of rTMS in the treatment of co-morbid anxiety in depressed patients with Parkinson's disease. Mov Disord. 2007:22:1836-6.

23. Vanderhasselt MA, Baeken C, Hendricks M, De Raedt R. The effects of high frequency rTMS on negative attentional bias are influenced by baseline state anxiety. Neuropsychologia. 2011;49:1824-30.
24. Baeken C, Vanderhasselt MA, De Raedt R. Baseline state anxiety influences HPA-axis sensitivity to one sham-controlled HF-rTMS session applied to the right dorsolateral prefrontal cortex. Psychoneuroendocrinology. 2011;36:60-7.

25. Vanderhasselt MA, Baeken C, De Raedt R. S17.3 Baseline state anxiety influences the effects of high frequency rTMS to the right prefrontal cortex on attentional processes for emotional material. Clin Neurophysiol. 2011;122:S40-1.

26. Balconi M, Ferrari C. RTMS stimulation on left dlpfc affects emotional cue retrieval as a function of anxiety level and gender. Depress Anxiety. 2012;29:976-82.

27. Fitzgerald PB, Hoy KE, Anderson RJ, Daskalakis ZJ. A study of the pattern of response to rTMS tratment in depression. Depress Anxiety. 2016;33:746-53

28. Zwanzger $\mathrm{P}$, Steinberg $\mathrm{C}$, Rehbein MA, Bröckelmann AK, Dobel C, Zavorotnyy $M$, et al. Inhibitory repetitive transcranial magnetic stimulation (rTMS) of the dorsolateral prefrontal cortex modulates early affective processing. Neuroimage. 2014;101:193-203.

29. Deppermann S, Notzon S, Kroczek A, Rosenbaum D, Haeussinger FB, Diemer J, et al. Functional co-activation within the prefrontal cortex supports the maintenance of behavioural performance in fear-relevant situations before an iTBS modulated virtual reality challenge in participants with spider phobia. Behav Brain Res. 2016;307:208-17.

30. Herrmann MJ, Katzorke A, Busch Y, Gromer D, Polak T, Pauli P, et al. Medial prefrontal cortex stimulation accelerates therapy response of exposure therapy in acrophobia. Brain Stimul. 2017;10:291-7.

31. Berger C, Domes G, Balschat J, Thome J, Höppner J. Effects of prefrontal rTMS on autonomic reactions to affective pictures. J Neural Transm. 2017:124:139-52.

32. Vennewald N, Winter B, Limburg K, Diemer J, Notzon S, Fohrbeck I, et al. Emotional processing and rTMS: does inhibitory theta burst stimulation affect the human startle reflex? J Neural Transm. 2016;123:1121-31.

33. Deppermann S, Notzon S, Britz R, Wirsing D, Kroczek A, Haeussinger $\mathrm{FB}$, et al. P73. Can iTBS modulate subjective and objective parameters of emotional processing in fear-relevant situations? A pilot study with spider phobics. Clin Neurophysiol. 2015;126:e130-1.

34. Notzon S, Deppermann S, Fallgatter A, Diemer J, Kroczek A, Domschke $\mathrm{K}$, et al. Psychophysiological effects of an iTBS modulated virtual reality challenge including participants with spider phobia. Biol Psychol. 2015;112:66-76

35. Downar J, Blumberger DM, Daskalakis ZJ. The neural crossroads of psychiatric illness: an emerging target for brain stimulation. Trends Cogn Sci. 2016;20:107-20

36. Pallanti S, Borgheresi A, Pampaloni I, Giovannelli F, Bernardi S, Cantisani A, et al. Motor cortex excitability correlates with novelty seeking in social anxiety: a transcranial magnetic stimulation investigation. J Neurol. 2010;257:1362-8.

37. Baeken C, De Raedt R, Van Schuerbeek $P$, Vanderhasselt MA, De Mey J, Bossuyt A, et al. Right prefrontal HF-rTMS attenuates right amygdala processing of negatively valenced emotional stimuli in healthy females. Behav Brain Res. 2010;214:450-5.

38. De Raedt R, Leyman L, Baeken C, Van Schuerbeek P, Luypaert R, Vanderhasselt MA, et al. Neurocognitive effects of HF-rTMS over the dorsolateral prefrontal cortex on the attentional processing of emotional information in healthy women: an event-related fMRI study. Biol Psychol. 2010;85:487-95

39. Mantovani A, Lisanby $\mathrm{SH}$, Pieraccini $F$, Ulivelli $M$, Castrogiovanni $\mathrm{P}$, Rossi S. Repetitive transcranial magnetic stimulation (rTMS) in the treatment of panic disorder (PD) with comorbid major depression. J Affect Disord. 2007;102:277-80.

40. Mantovani A, Aly M, Dagan Y, Allart A, Lisanby SH. Randomized sham controlled trial of repetitive transcranial magnetic stimulation to the dorsolateral prefrontal cortex for the treatment of panic disorder with comorbid major depression. J Affect Disord. 2013:144:153-9.

41. Zwanzger P, Eser D, Völkel N, Baghai TC, Möller HJ, Rupprecht R, et al. Effects of repetitive transcranial magnetic stimulation (rTMS) on panic attacks induced by cholecystokinin-tetrapeptide (CCK-4). Int J Neuropsychopharmacol. 2007;10:285-9.

42. Machado S, Santos V, Paes F, Arias-Carrión O, Carta MG, Silva AC, et al. Repetitive transcranial magnetic stimulation (rTMS) to treat refractory panic disorder patient: a case report. CNS Neurol Disord Drug Targets. 2014;13:1075-8.

43. Deppermann S, Vennewald N, Diemer J, Sickinger S, Haeussinger FB, Notzon S, et al. Does rTMS alter neurocognitive functioning in patients with panic disorder/agoraphobia? An fNIRS-based investigation of prefrontal activation during a cognitive task and its modulation via sham-controlled rTMS. Biomed Res Int. 2014;2014:542526.

44. Li H, Wang J, Li C, Xiao Z. Repetitive transcranial magnetic stimulation (rTMS) for panic disorder in adults. Cochrane Database Syst Rev. 2014;2014:CD009083.

45. Balderston NL, Beydler EM, Goodwin M, De Deng Z, Radman T, Luber $B$, et al. Low-frequency parietal repetitive transcranial magnetic stimulation reduces fear and anxiety. Transl Psychyatry. 2020;10. https://doi. org/10.1038/s41398-020-0751-8. 